\title{
An Optimization Based Algorithm for Allocation of Distribution Generation and to determine impact of DG Penetration Level in RDS
}

\author{
${ }^{1}$ Y. Anil Kumar, ${ }^{2}$ N. Prema Kumar \\ Department of Electrical Engineering, AU College of Engineering, Visakhapatnam
}

Received: $10^{\text {th }}$ Feb 2018, Accepted: $1^{\text {th }}$ March 2018, Published: 30 ${ }^{\text {th }}$ April 2018

\begin{abstract}
With increasing demand on conventional distribution systems, distributed energy sources are placed near the consumer premises to maintain the reliability of supply. DG also includes the benefits of reduced power loss, improved voltage profile and also reduced transmission and distribution costs. Placement of DG sources have some impact on existing distribution system. The impacts may be technical, economical or environmental. In this paper we have introduced technical and economic benefits of DG. Planning of DG size and location is necessary to obtain the satisfactory performance. In this paper inertia weight particle swarm optimization (IPSO) algorithm is used to minimize the objective function. In this IPSO method, DGs are randomly placed and size is obtained then these results are compared with previous results then optimal location and sizes are obtained. Here, objective function is the function of impact indices on distribution system due to placement of DG Forward-backward sweep method is considered for studying the load flow of radial distribution system over various techniques available.
\end{abstract}

Keywords: Distributed Generation(DG), Power Flow, Placement And Sizing, Improved Particle Swarm Optimization (IPSO), Objective function

\section{Introduction}

Now a days electricity demand is increasing rapidly, with this increasing demand on the distribution system, losses also increases hence voltage profile will become poor. To overcome this, distributed sources are provided over conventional generating stations because of the improved technical, economical and environmental benefits. Integration of DGs in distribution system leads to reduced loss and improved voltage profile. Distributed generators are the smallest generating units placed near the consumer premises by the consumer itself or by the generation capacity is range from 1 kilowatt to 10 Megawatts. DG technologies may be renewable or non-renewable. But renewable sources like wind or solar power technologies are preferred due to its environmental benefits.

\section{Impact Indices}

There are several impact indices in order to describe the impacts on distribution system due to the presence of DG. In this paper, three indices will be
Computed in order to describe their effect due to the presence of DG. These indices are defined as follows

2.1 Real Power Loss Index (ILP): The real power loss index is defined as $* 97 \backslash-8+96$

$\mathrm{ILP}=\left[\mathrm{P}_{\mathrm{LDG}}\right] /\left[\mathrm{P}_{\mathrm{L}}\right]$

(1)

where $\mathrm{P}_{\mathrm{LDG}}$ and $\mathrm{P}_{\mathrm{L}}$ are the real power losses with $\mathrm{DG}$ and without DG in the distribution system.

2.2 Voltage Deviation Index (IVD): One of the advantages of proper location and size of the DG is the improvement in voltage profile. this index can be defined as

IVD $=\sum_{\mathrm{i}=1}^{\mathrm{n}} \frac{\text { Vref-Vi }}{\text { Vref }}$

(2)

where $\mathrm{n}$ is the no of buses. the Vref and Vi are the reference voltage and system bus voltages in p.u respectively. The minimum value of IVD indicates the performance of the distribution is better.

2.3 Cost of Energy Losses (CL): The annual cost of energy loss is given by

$$
\mathrm{CL}=(\mathrm{TRPL}) *(\mathrm{Kp}+\mathrm{Ke} * \mathrm{Lsf} * 8760) \$
$$

(3)

Where TRPL: Total Real Power Losses Kp: annual demand cost of power loss $(\$ / \mathrm{kW}) \mathrm{Ke}$ : annual cost of energy loss ( $\$ / \mathrm{kW} \mathrm{h}$ ) Lsf: loss factor. Loss factor is expressed in terms of load factor (Lf) as below

$\mathrm{Lsf}=\mathrm{k} * \mathrm{Lf}+(1-\mathrm{k}) * \mathrm{Lf} 2$

(4)

The values taken for the coefficients in the loss factor calculation are: $\mathrm{k}=0.2, \mathrm{Lf}=0.47, \mathrm{Kp}=57.6923$ $\$ / \mathrm{kW}, \mathrm{Ke}=0.00961538 \$ / \mathrm{kW} \mathrm{h}$.

\section{Problem Form.01.2ulation}

3.1 Single objective problem formulation

The objective is to determine combination of optimal location and size of distributed generators that minimize the indices individually under system constraints. The operating constraints are power balance, voltage profile of the system feeder and radial structure of the distribution system. The objective function for the minimization is described as follows:

$$
\mathrm{F}=\min (\text { index }) \quad \ldots . . \text { with DGs }
$$

(5) 
Subjected to constraints:

Power balance constraints: $\sum \mathrm{P}_{\mathrm{DGi}}=\sum \mathrm{P}_{\mathrm{Di}}(6)$

Voltage limits: $\quad V_{\min } \leq V_{i} \leq V_{\max }$

Vmin and Vmax is minimum and maximum voltage limits of ith bus

Real power generation limits:

$\mathrm{P}_{\mathrm{DGmin}} \leq \mathrm{P}_{\mathrm{DGi}} \leq \mathrm{P}_{\mathrm{DG} \text { max }}$

(8)

Reactive power generation limits:

$\mathrm{Q}_{\mathrm{DGmin}} \leq \mathrm{Q}_{\mathrm{DGi}} \leq \mathrm{Q}_{\mathrm{DGmax}}$

(9)

\section{Multi Objective Problem Formulation}

Solving multi objective problems has traditionally consisted of converting all objectives into a single objective function. The ultimate goal is to find the solution that minimizes or maximizes this single objective while maintaining the system constraints. The optimization solution results in a single value that reflects a compromise between all objectives. A simple and still very popular method is the weighted aggregation method. This is a special case of the utility function method, which converts the multi objective problem into a single objective problem by applying weights to each individual objective vector. In this paper, optimal placement and sizing of distributed generators in a radial distribution system is determined by multi-objective optimization approach. A multi-objective function is designed to minimize real power loss of the system and maximize the voltage profile of the system under different system constraints. Designed multiobjective function is optimized using inertia weight particle swarm optimization method (IPSO).

The multi objective problem is to determine optimal location and size of DG units which minimizes the total real power losses and to improve the voltage profile of the system under different system operating constraints. The operating constraints are voltage profile of the system, radial structure of the distribution system, real and reactive power generation limits and power balance constraint. The objective function of the problem is

$\mathrm{f}_{1}=\min (\mathrm{ILP})$

(10)

$\mathrm{f}_{2}=\min (I V D)$

(11)

$\mathrm{f}_{3}=\min (\mathrm{CL})$

(12)

$\sum_{\mathrm{i}=1}^{\mathrm{n}} \mathrm{W}_{\mathrm{i}}=1$, where $\mathrm{W}_{\mathrm{i}} \in[0,1]$

$\mathrm{F}(\mathrm{i})=\mathrm{W}_{\mathrm{i}} *$ (Performance Indices $)$

(14) Here $i=1,2,3 \ldots \ldots$ n-number of nodes and
$\mathrm{W}$ is the weighing factor which tells that which index should get more importance and also

$\mathrm{f}_{1}, \mathrm{f}_{2}, \mathrm{f}_{3}$, are three different objective functions, using weight factor method multi objective function is expressed as follows

$\mathrm{f}_{\mathrm{mo}}=\mathrm{W}_{1} * \mathrm{f}_{1}+\mathrm{W}_{2} * \mathrm{f}_{2}+\mathrm{W}_{3} * \mathrm{f}_{3}$

(15) where $\mathrm{W} 1, \mathrm{~W} 2$, and $\mathrm{W} 3$ are weight factors assigned to impact indices .

Minimize $f=\min \left(f_{\text {mo }}\right)$

(16) Subjected to constraints given in equations (6), (7), (8) and (9)

\section{Practice Swarm Optimization (PSO)}

Particle swarm optimization (PSO) algorithm is a population based optimization method that has gained much popularity among researchers since after its introduction. The algorithm mimics bird's behavior during flight in space. Each of the bird in the aggregation of the birds called swarm is represented as a particle. These particles that form the swarm searches for food based on their own experience and that of the other particles within the same swarm. The PSO have been studied by many researchers and several newer versions have been developed for applications in different real-world problems and are found to be robust and fast in solving nonlinear non-differentiable multimodal problems. The search process is similar to the social behavior of flying birds when searching for food.

The individual bird called particles or swarm flies in the optimization problem hyperspace to search for optimal food location. The position and velocity of the particles is always changing and adjusted according to the cooperative communication among the particles and each individual's own experience simultaneously. Therefore the particle changes position by balancing its social and individual experience.

Initialize randomly generated solution with set of particles.

Let, $\mathrm{X}_{\mathrm{m}}^{\mathrm{k}}=$ position of the particles

$V_{m}=$ velocity of particles

The velocity of the particle:

$V_{m}^{k+1}=\omega V_{m}^{k}+C_{1} \operatorname{rand}\left(\right.$ pbest $\left.t_{m}^{k}-X_{m}^{k}\right)+$ $\mathrm{C}_{2} \operatorname{rand}\left(\right.$ gbest $\left.^{\mathrm{k}}-\mathrm{X}_{\mathrm{m}}^{\mathrm{k}}\right)$

$\omega=\omega_{\max }-\frac{\left(\omega_{\max }-\omega_{\min }\right)}{\text { iter }_{\max }} *$ iter

Where, $\omega=$ inertia weight

$\mathrm{V}_{\mathrm{m}}^{\mathrm{k}}=$ previous particle velocity

$\mathrm{C}_{1}, \mathrm{C}_{2}=$ acceleration coefficients generally taken in between $[1,2]$ 
pbest $\mathrm{m}_{\mathrm{m}}^{\mathrm{k}}=$ personnel best of the particle ' $\mathrm{m}$ ' based on own experience

gbest $\mathrm{m}_{\mathrm{m}}^{\mathrm{k}}=$ global best of the particle ' $\mathrm{m}$ ' referred to entire swarm

Update the position of the particle by using Eq

$X_{j}^{k+1}=X_{j}^{k}+V_{j}^{k+1}$

(19)

\section{Implementation of IPSO algorithm}

The flowchart for implementation of IPSO algorithm is shown in figure 1 and the algorithm was presented in the following

Step 1: Read the input system data and initialize population, number of particles, limits of DG size, voltage limits, parameters of algorithm etc.

Step 2: Calculation of objective function equation by using Forward-Backward sweep based distribution load flow.

Step 3: Calculation of pbest i.e. objective function related to each particle in the population of the current iteration is compared with it in the previous iteration and the position of the particle enjoying a lower objective function as pbest for the current iteration is recorded:

$$
\text { pbest }_{\mathrm{m}}^{\mathrm{k}+1}= \begin{cases}\text { pbest } & \mathrm{k} \\ \mathrm{x}_{\mathrm{m}}^{\mathrm{k}+1} & \text { if } \mathrm{f}_{\mathrm{m}}^{\mathrm{k}+1} \geq \mathrm{f}_{\mathrm{m}}^{\mathrm{k}} \\ \mathrm{f} & \text { if } \mathrm{f}_{\mathrm{m}}^{\mathrm{k}}\end{cases}
$$

Where, $\mathrm{k}$ is the number of iterations, and $\mathrm{f}$ is objective function evaluated for the particle.

Step 4: Calculation of gbest i.e. the best objective function associated with the pbest among all particles in the current iteration is compared with that in the previous iteration and the lower value is selected as the current overall gbest.

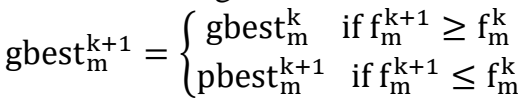

Step 5: Velocity updating, after calculation of the pbest and gbest the velocity of particles for the next iteration should be modified by using equations (17) and inertia weight (18)

Step 6: Check the velocity components constraints occurring in the limits from the following conditions,

If $\mathrm{Vid}>\mathrm{Vmax}$, then $\mathrm{Vid}=\mathrm{Vmax}$ (or) If $\mathrm{Vid}<-$ $\mathrm{V} \max$ then $\mathrm{Vid}=-\mathrm{V} \max$

(22)

Step 7: Position updating, the position of each particle at the next iteration $(\mathrm{k}+1)$ is modified using equation (19)

Step 8: If the number of iterations reaches the maximum i.e. iter $=$ itermax, then go to step 9 . Otherwise, go to step 2.
Step 9: The individual that generates the latest gbest is the optimal locations and sizes of DGs with minimum power loss.

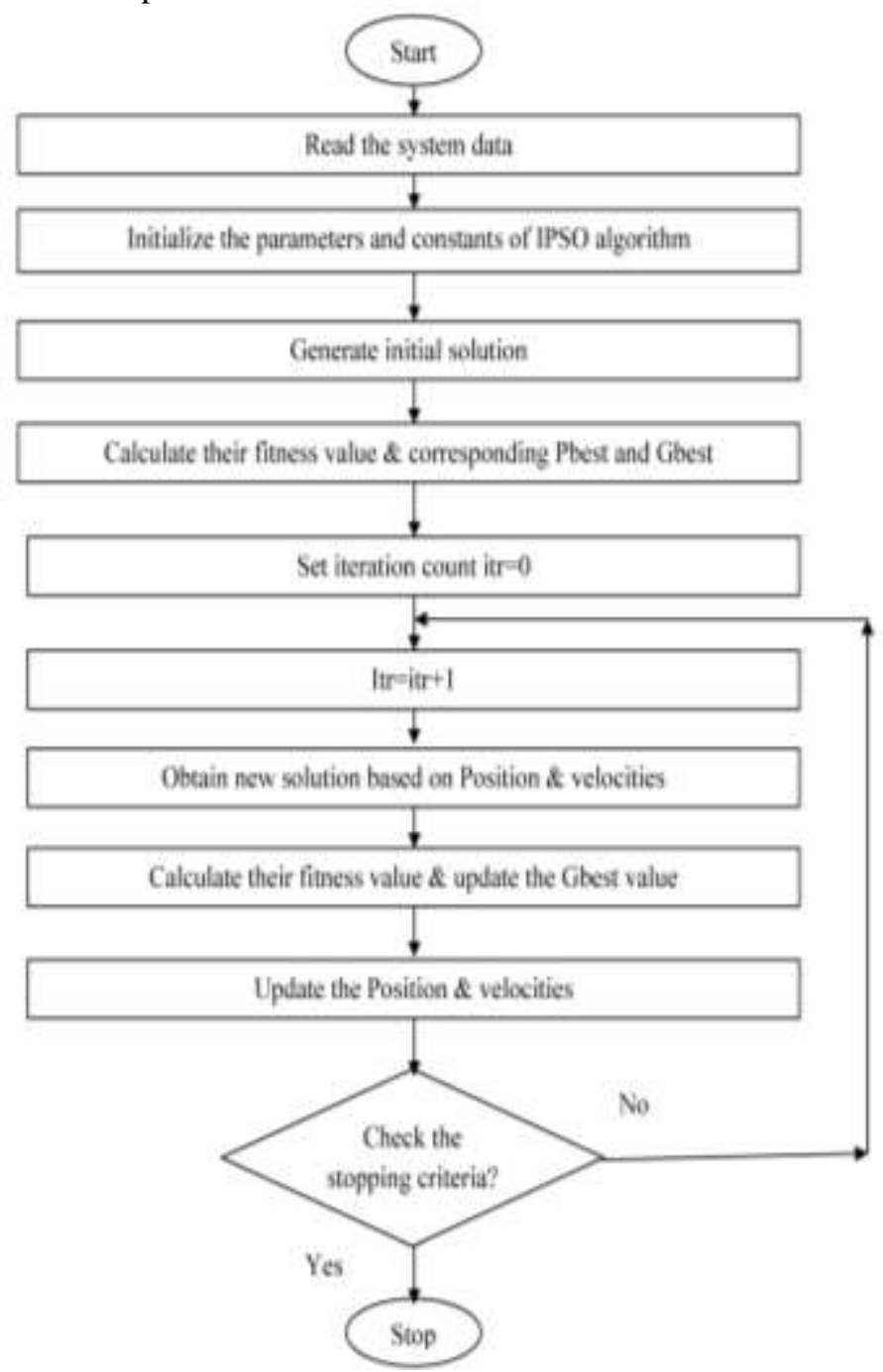

\section{Results and Discussion}

Fig. 1 Flowchart for IPSO algorithm

\subsection{Test System}

The IPSO algorithm for distribution system was tested the 33 bus systems. The 33 bus system has 32 sections with the total load 3.72 MW and 2.3MVar. the minimum and maximum voltage values are set at 0.95 nd 1.05 p.u respectively. the base values used are 100MVA and $12.66 \mathrm{kV}$. A DG size is considered in a range of $0.1 \mathrm{MW}$ to $1.2 \mathrm{MW}$. Results obtained from the load flow before and after placement of DG for the 33-bus radial distribution system are as shown below in the table1.

The reduction in the real power loss and improvement in voltage profile after placing DG in distribution system can be observed from table and waveforms.

TABLE 1 LOAD FLOW RESULTS BEFORE AND AFTER PLACING DG OF A 33-BUS SYSTEM

\begin{tabular}{|l|l|l|}
\hline & Without DG & With DG \\
\hline
\end{tabular}


Helix Vol. 8(3):3356-3361

\begin{tabular}{|c|c|c|c|c|}
\hline $\begin{array}{l}\text { Bus } \\
\text { No }\end{array}$ & $\begin{array}{c}\text { Voltage } \\
\text { (p.u) }\end{array}$ & $\begin{array}{c}\text { Power } \\
\text { Loss(MW) }\end{array}$ & $\begin{array}{c}\text { Voltage } \\
\text { (p.u) }\end{array}$ & $\begin{array}{c}\text { Power } \\
\text { Loss(MW) }\end{array}$ \\
\hline 1 & 1.0000 & 0 & 1.0000 & 0 \\
\hline 2 & 0.9970 & 1.2292 & 0.9986 & 0.3992 \\
\hline 3 & 0.9829 & 5.2036 & 0.9931 & 1.5580 \\
\hline 4 & 0.9754 & 2.0033 & 0.9901 & 0.6651 \\
\hline 5 & 0.9680 & 1.8830 & 0.9874 & 0.6075 \\
\hline 6 & 0.9495 & 3.8524 & 0.9792 & 1.2380 \\
\hline 7 & 0.9460 & 0.1944 & 0.9768 & 0.0449 \\
\hline 8 & 0.9323 & 1.1859 & 0.9722 & 0.2085 \\
\hline 9 & 0.9260 & 0.4260 & 0.9713 & 0.0718 \\
\hline 10 & 0.9202 & 0.3615 & 0.9709 & 0.0737 \\
\hline 11 & 0.9193 & 0.0564 & 0.9710 & 0.0152 \\
\hline 12 & 0.9178 & 0.0898 & 0.9714 & 0.0302 \\
\hline 13 & 0.9116 & 0.2717 & 0.9728 & 0.1359 \\
\hline 14 & 0.9093 & 0.0743 & 0.9734 & 0.0601 \\
\hline 15 & 0.9079 & 0.0364 & 0.9720 & 0.0318 \\
\hline 16 & 0.9065 & 0.0287 & 0.9707 & 0.0250 \\
\hline 17 & 0.9045 & 0.0256 & 0.9688 & 0.0224 \\
\hline 18 & 0.9038 & 0.0054 & 0.9683 & 0.0047 \\
\hline 19 & 0.9965 & 0.0161 & 0.9981 & 0.0160 \\
\hline 20 & 0.9929 & 0.0832 & 0.9945 & 0.0829 \\
\hline 21 & 0.9922 & 0.0101 & 0.9938 & 0.0100 \\
\hline 22 & 0.9916 & 0.0044 & 0.9932 & 0.0043 \\
\hline 23 & 0.9793 & 0.3181 & 0.9918 & 0.0645 \\
\hline 24 & 0.9726 & 0.5143 & 0.9897 & 0.0936 \\
\hline 25 & 0.9693 & 0.1287 & 0.9909 & 0.0990 \\
\hline 26 & 0.9476 & 0.2599 & 0.9787 & 0.1244 \\
\hline 27 & 0.9450 & 0.3327 & 0.9782 & 0.1685 \\
\hline 28 & 0.9336 & 1.1294 & 0.9744 & 0.6130 \\
\hline 29 & 0.9254 & 0.7828 & 0.9719 & 0.4638 \\
\hline 30 & 0.9218 & 0.3893 & 0.9720 & 0.2823 \\
\hline 31 & 0.9176 & 0.1593 & 0.9680 & 0.1432 \\
\hline 32 & 0.9167 & 0.0213 & 0.9672 & 0.0192 \\
\hline 33 & 0.9164 & 0.0013 & 0.9669 & 0.0012 \\
\hline
\end{tabular}

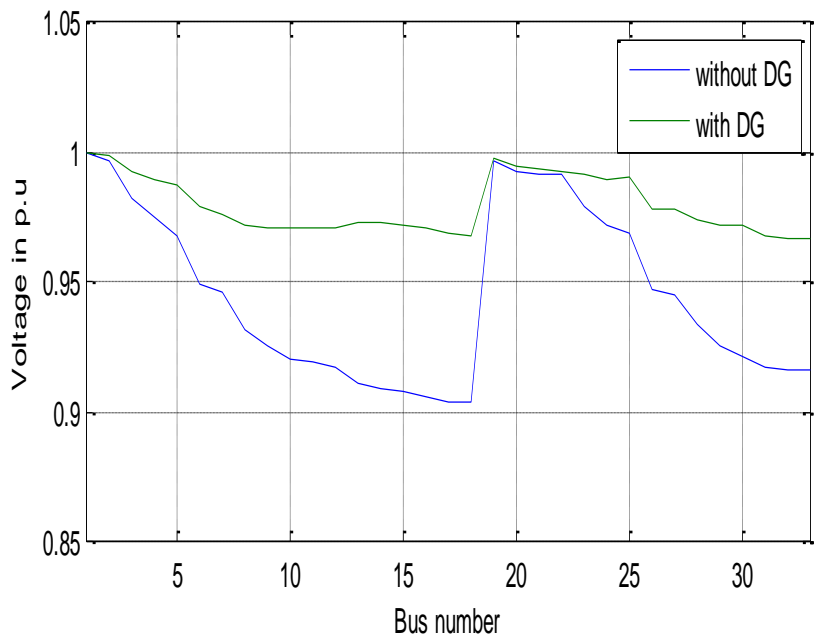

Fig. 2 Voltage Profile of 33-bus system

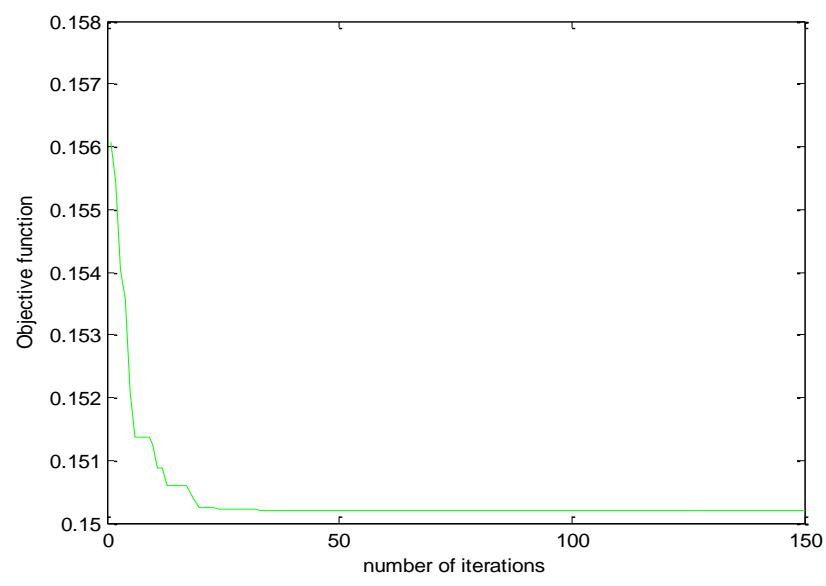

Fig. 3 Convergence Characteristics Of 33-Bus System

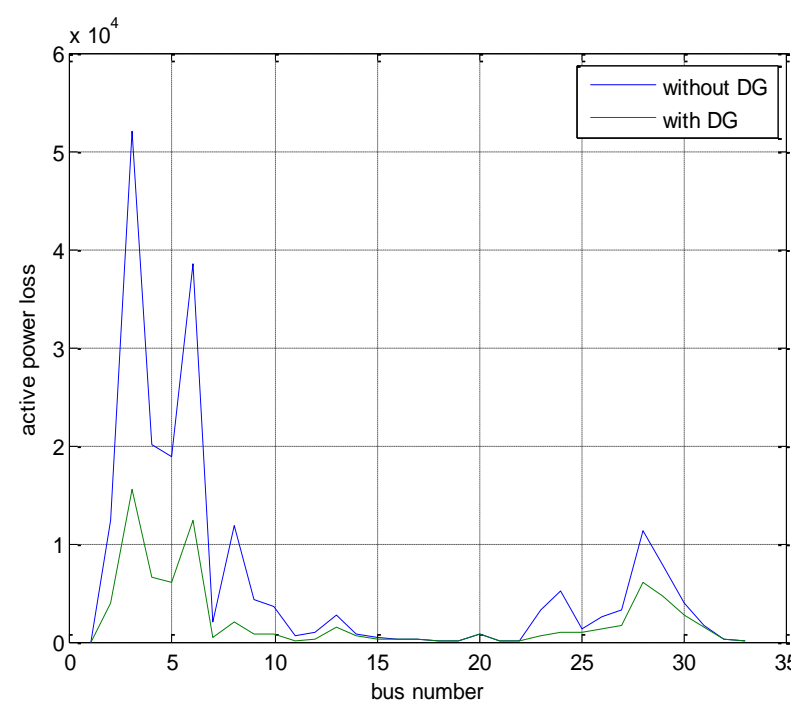

Fig. 4 Real Power Loss of 33-bus system

\section{Conclusion}


In this paper, multi-objective optimization problem is formulated to determine the optimal location and sizing of DG by considering various impact indices (like active power loss index, voltage deviation index, and cost of energy losses in distribution system due to presence of distributed generation) as objective function with pre-specified constraints such as voltage and active power limits. Multiobjective function for this proposed method is a combination of these three impact indices. IPSO (inertia weight particle swarm optimization) algorithm is used to solve this optimization problem and obtained optimal location and sizing of DG for IEEE 33-bus radial distribution system. The results are compared with forward and backward sweep algorithm. Results obtained shows that voltage profile is improved, real power losses are decreased and also cost of energy losses are reduced after placing DG.

\section{Reference}

[1] Sweta, Mohamed Samir "A Generalized Overview of Distributed Generation" International Journal of Emerging Research in Management \&Technology ISSN: 2278-9359 (Volume-2, Issue-12).

[2] Singiresu. S. Rao "engineering optimization" theory and practice fourth edition.

[3] D. Sai Krishna Kanth, Dr. M. Padma Lalita, P. Suresh Babu " Siting \& Sizing of Dg for Power Loss \& Thd Reduction, Voltage Improvement Using PSO \& Sensitivity Analysis" International Journal of Engineering Research and Development Volume 9, Issue 6 (December 2013), PP. 01-07.

[4] C. Divya, Dr.T.Gowri manohar "Optimal Location of DG Units using Sensitivity Analysis" international journal of advance technology and innovative research.

[5] S K Saha S Banerjee, D Maity, C K Chanda "Optimal Sizing and Location Determination of Distributed Generation in Distribution Networks" 978-1-4678-6503-1/15/\$31.00 (C) 2015 IEEE transactions.

[6] Arulraj R, N Kumarappan, Senior Member, IEEE, and Vigneysh T "Optimal Location and Sizing of DG and Capacitor in Distribution Network Using Weight-Improved Particle Swarm Optimization Algorithm (WIPSO)" IEEE transactions.

[7] L. Y. Wong, Siti Rafidah Abdul Rahim, Mohd Herwan Sulaiman, O. Aliman "Distributed Generation Installation Using Particle Swarm Optimization" The 4th International Power Engineering and Optimization Conf.

[8] J. A. Sa'ed, N. Ismail, S. Favuzza, M. G. Ippolito, F. Massaro "Effect of Voltage Deviations on Power Distribution Losses in Presence of DG Technology" 4th international conference on renewable energy research and application palermo.

[9] A. D. Rana, J. B. Darji, Mosam Pandya "Backward / Forward Sweep Load Flow, Algorithm for Radial Distribution System" IJSRD - International Journal for Scientific Research \& Development| Vol. 2, Issue 01, 2014 | ISSN (online): 2321-0613.

[10] Hussein. A. Attia, M. El-Shibini, Z.H. Osman, and Ahmed A. Moftah "An Assessment of a Global Performance Index for Distributed
Generation Impacts on Distribution Systems" Proceedings of the 14th International Middle East Power Systems Conference (MEPCON'10), Cairo University, Egypt, December 19-21, 2010, Paper ID 310.

[11] MCV Suresh and Belwin Edward J “Optimal Placement Of Distributed Generation In Distribution Systems By Using Shuffled Frog Leaping Algorithm" VOL. 12, NO. 3, FEBRUARY 2017 ISSN 1819-6608 ARPN Journal of Engineering and Applied Sciences.

[12] Alireza Askarzadeh and Alireza Rezazadeh "An Innovative Global Harmony Search Algorithm for Parameter Identification of a PEM Fuel Cell Model" IEEE transactions on industrial electronics, vol. 59, no. 9, September 2012 3473.

[13] Dexuan Zoua, Liqun Gaoa, Steven Li b, Jianhua Wua, Xin Wangc "A novel global harmony search algorithm for task assignment problem" The Journal of Systems and Software 83 (2010) 1678-1688.

[14] Injeti Satish Kumar and Prema Kumar Navuri "Optimal Access Point and Capacity of Distributed Generators in Radial Distribution Systems for Loss Minimization Including Load Models" Distributed Generation and Alternative Energy Journal Vol. 29, No. 22014.

[15] V. V. S. N. Murty, B. Ravi Teja, and Ashwani Kumar, A Contribution to Load Flow in Radial Distribution System and Comparison of Different Load Flow Methods, International Conference on Power, Signals, Controls and Computation (EPSCICON), 8 - 10 January 2014.

[16]S. Ghosh and D. Das, "Method for load-flow solution of radial distribution network," IEEE Proc.-Generation, Transmission and Distribution. vol. 146, no. 6,Nov. 1999.

[17] Rajkumar Viral n, D.K.Khatod, ”Optimal planning of distributed generation systems in distribution system: A review", Elsevier Ltd, Renewable and Sustainable Energy Reviews 16 (2012) pg no.5146-5165.

[18] Naveen Jain, S.N. Singh,and S.C. Srivastava, Particle Swarm Optimization Based Method for Optimal Siting and Sizing of Multiple Distributed Generators, 16th national power systems conference, 15th-17th december, 2010.

[19] Praveen Kumar Sharma, Mr.Nitin Singh,optimal allocation of $\mathrm{dg}$ in radial distribution networks, international journal of research review in engineering science \& technology (issn 2278-6643) volume-4, issue2, june 2015.

[20] Mohamed Imran , Kowsalya M, Optimal size and siting of multiple distributed generators in distribution system using bacterial foraging optimization, Elsevier Swarm and EvolutionaryComputation15 (2014) 58-65.

[21] H. Manafi, N. Ghadimi, M. Ojaroudi, P. Farhadi, Optimal Placement Of Distributed Generations In Radial Distribution Systems Using Various Pso And De Algorithms, Electronics And Electrical Engineering, Issn 1392-1215, Vol. 19, No. 10, 2013.

[22] KhyatiMistry, Ranjit Roy, CRPSO based Optimal Placement of Multi-Distributed Generation in Radial Distribution System, 2012 IEEE International Conference on Power and Energy (PECon), 2-5 December 2012, Kota Kinabalu Sabah, Malaysia. 
[23] M.P.Lalitha, V.C.Veera Reddy, V.Usha, Optimal DG placement for minimum real power loss in radial distribution systems using PSO, Journal of Theoretical and Applied Information Technology,pp.107-116,2010.

[24] Deependra Singh, Devender Singh, and K. S. Verma, Multiobjective Optimization for DG Planning With Load Models, ieee transactions on power systems, vol. 24, no. 1, february 2009.

[25] S K Injeti, N P Kumar, 'Planning and operation of active radial distribution networks for improved voltage stability and loss reduction', World Journal of Modeling and Simulation, Vol.8, No.3, 2012, pp. 211-222.

[26] J. Kennedy and R. C. Eberhart, "Particle swarm optimization", Proceedings of the IEEE International Conference on Neural NetworksIV, Piscataway, NJ: IEEE Service Center, pp. 1942-1948, 1995.
[27]Y. Shi and R. Eberhart., "A modified particle swarm optimizer", In Evolutionary Computation Proceedings, 1998. IEEE World Congress on Computational Intelligence.,The 1998 IEEE International Conference on, pages 69-73. IEEE, 2002.

[28] J. Xin, G. Chen, and Y. Hai., "A Particle Swarm Optimizer with Multistage Linearly-Decreasing Inertia Weight", In Computational Sciences and Optimization, 2009. CSO 2009. International Joint Conference on, volume 1, pages 505-508. IEEE, 2009.

[29] N. Ameir Ahmad ,Ismail Musirin,S. I. Sulaiman, Exponential Based PSO Performed on DG Installation for Loss Minimization Considering THD, IEEE 8th International Power Engineering and Optimization Conference (PEOCO2014), Langkawi, The Jewel of Kedah, Malaysia. 24-25 March

\begin{tabular}{|c|c|c|c|c|c|c|c|c|c|}
\hline \multirow{2}{*}{$\begin{array}{l}\text { Bus } \\
\text { No. }\end{array}$} & \multicolumn{9}{|c|}{ Rated capacity of DG in percentage of total load } \\
\hline & $\mathbf{0 \%}$ & $10 \%$ & $20 \%$ & $30 \%$ & $40 \%$ & $50 \%$ & $60 \%$ & $70 \%$ & $\mathbf{8 0 \%}$ \\
\hline 2 & 10.09 & 9.91 & 9.73 & 9.57 & 9.42 & 9.29 & 9.18 & 9.09 & 9.01 \\
\hline 3 & 10.09 & 9.74 & 9.39 & 9.09 & 8.82 & 8.58 & 8.39 & 8.22 & 8.09 \\
\hline 4 & 10.09 & 9.47 & 8.89 & 8.39 & 7.94 & 7.57 & 7.25 & 7.00 & 6.81 \\
\hline 5 & 10.09 & 9.24 & 8.46 & 7.78 & 7.20 & 6.71 & 6.31 & 6.00 & 5.77 \\
\hline 6 & 10.09 & 9.01 & 8.05 & 7.22 & 6.51 & 5.93 & 5.46 & 5.11 & 4.87 \\
\hline 7 & 10.09 & 8.88 & 7.84 & 7.00 & 6.33 & 5.84 & 5.51 & 5.33 & 5.30 \\
\hline 8 & 10.09 & 8.81 & 7.75 & 6.92 & 6.30 & 5.88 & 5.66 & 5.61 & 5.73 \\
\hline 9 & 10.09 & 8.74 & 7.67 & 6.88 & 6.36 & 6.07 & 6.01 & 6.17 & 6.52 \\
\hline 10 & 10.09 & 8.71 & 7.65 & 6.91 & 6.46 & 6.27 & 6.34 & 6.63 & 7.14 \\
\hline 11 & 10.09 & 8.70 & 7.66 & 6.96 & 6.56 & 6.44 & 6.58 & 6.97 & 7.58 \\
\hline 12 & 10.09 & 8.71 & 7.69 & 7.02 & 6.67 & 6.61 & 6.82 & 7.28 & 7.97 \\
\hline 13 & 10.09 & 9.74 & 9.42 & 9.17 & 8.97 & 8.83 & 8.75 & 8.72 & 8.75 \\
\hline 14 & 10.09 & 9.74 & 9.47 & 9.28 & 9.18 & 9.17 & 9.24 & 9.39 & 9.62 \\
\hline 15 & 10.09 & 9.75 & 9.49 & 9.34 & 9.30 & 9.35 & 9.49 & 9.73 & 10.06 \\
\hline 16 & 10.09 & 9.75 & 9.51 & 9.38 & 9.36 & 9.44 & 9.62 & 9.91 & 10.29 \\
\hline 17 & 10.09 & 8.83 & 7.74 & 6.81 & 6.04 & 5.43 & 4.96 & 4.64 & 4.46 \\
\hline 18 & 10.09 & 8.69 & 7.48 & 6.48 & 5.67 & 5.05 & 4.61 & 4.33 & 4.21 \\
\hline 19 & 10.09 & 8.52 & 7.20 & 6.13 & 5.29 & 4.68 & 4.28 & 4.08 & 4.06 \\
\hline 20 & 10.09 & 8.39 & 6.98 & 5.87 & 5.03 & 4.44 & 4.09 & 3.97 & 4.05 \\
\hline 21 & 10.09 & 8.27 & 6.80 & 5.66 & 4.83 & 4.29 & 4.01 & 3.97 & 4.16 \\
\hline
\end{tabular}

APPENDIX - 1 ANALYSIS OF PENETRATION

LEVEL OF DG VS \% OFREAL POWER LOSSES IN A RDS 